Proc. Indian Acad. Sci. (Chem. Sci.), Vol. 98, Nos 5 \& 6, June 1987, pp. 453-468.

(C) Printed in India.

\title{
Solubilization of bilirubin by cholate micelles. Spectroscopic and gel permeation studies
}

\author{
KASTURI LAHIRI PURANAM and P BALARAM \\ Molecular Biophysics Unit, Indian Institute of Science, Bangalore 560 012, India
}

\begin{abstract}
The interactions of bilirubin with bile salts have been studied using fluorescence, circular dichroism and 'H NMR methods. Enhancement of bilirubin fluorescence and induction of optical activity in bilirubin in the presence of cholate has been observed. Fluorescence enhancement is pronounced above the critical micelle concentration, while induced CD bands are detectable even in the premicellar region. Dehydrocholate and deoxycholate did not cause a fluorescence increase, but induced CD bands were observed for bilirubin in these cases. Gel permeation chromatography on Sephadex G-50 yielded a single bilirubin-cholate species at alkaline pH, while two species were obtained at neutral $\mathrm{pH}$. 'H NMR and'CD spectral characterizations of these complexes are reported. A 4:1 cholate-bilirubin mixture has been analysed by difference (nuclear Overhauser effect) NOE spectroscopy. Observation of strong, negative NOE, both intermolecular and intramolecular leads to the coeclusion chat specific methyl groups on bilirubin and cholate are proximal in the mixed micelle.
\end{abstract}

Keywords. Bilirubin; bile salts; micelles; induced circular dichroism; fluorescence; nuclear Overhauser effects.

\section{Introduction}

An important aspect of biliary physical chemistry is the physical state of organic anions in bile. Bilirubin is one of the most thoroughly studied anions because of its biological and clinical importance. Other anions are drugs and dyes like indocyanine green, bromsulphphthalein, rose bengal etc. Many of these are incorporated into mixed micelles of lipids and bile acids (Bickel and Minder ,1970; Scharschmidt and Schrnid 1978; Reuben et al 1982). A physical association with lipid micelles helps in the effective excretion of the xenobiotics in bile (Reuben 1984).

Bilirubin IX $\alpha$ is the end product of heme degradation in mammals (Brown and Troxler 1982) which has necessarily to be excreted as it serves no useful purpose and is neurotoxic. Bilirubin is practically insoluble under physiological conditions and is transported in blood as the serum albumin complex (Meuwissen and Heirwegh 1982) to the liver, where it undergoes conjugation with glucuronic aci'd to form the more soluble diglucuronides. In the case of bilirubin, the rate of biliary secretion has been shown to rise with an increase in biliary output of bile salts (Goresky et al 1974). The solubility of bilirubin has been found to be enhanced in the presence of bile salts (Carey and Koretsky 1979; Ostrow and Celic 1984). Bilirubin is therefore thought to be associated with mixed micelles of lecithin and bile salts. However, structural details of such an interaction between bilirubin and 
bile salts are lacking and that has prompted us to undertake a spectroscopic investigation of this system. This report summarizes fluorescence, circular dichroism (CD), gel permeation and ${ }^{1} \mathrm{H}$ NMR studies of bilirubin-bile salt complexes.

\section{Materials and methods}

Bilirubin obtained from Sigma Chemical Co. was purified according to the procedure of McDonagh and Assisi (1972). Cholic acid, dehydrocholic acid and sodium deoxycholate were also from Sigma. Both cholic acid and dehydrocholic acid were converted into their sodium salts by adding a molar equivalent of sodium hydroxide and subsequent lyophilization.

Aqueous stock solutions of bilirubin were prepared using sodium hydroxide for complete dissolution. The concentration of such stock solutions was determined using $\varepsilon_{438}=47,000 \mathrm{M}^{-1} \mathrm{~cm}^{-1}$ (Carey and Koretsky 1979). The solutions were used within two to three hours of preparation. Samples containing bilirubin and cholate for ${ }^{1} \mathrm{H}$ NMR studies were made by addition of solid bilirubin to the cholate solution in $\mathrm{D}_{2} \mathrm{O}$ and then increasing the $\mathrm{pD}$ of the solution to $\sim 10.5$ using $\mathrm{NaOD}$, when all the bilirubin dissolves. Such samples could be stored in the dark, at $4^{\circ} \mathrm{C}$, for at least days without the occurrence of bilirubin photodegradation.

For the fluorescence and $\mathrm{CD}$ experiments the final concentration of bilirubin used was always less than $1 \times 10^{-5} \mathrm{M} .1 \mathrm{~cm}$ pathlength cuvettes were used for the fluorescence experiments, while for the $C D$ experiments a $5 \mathrm{~cm}$ pathlength, cylindrical cell was employed. Fluorescence studies were carried out on Perkin Elmer MPF 44A and Hitachi 650-60 fluorimeters and CD studies on a JASCO J20 spectropolarimeter.

Gel permeation studies were done on a Sephadex G-50 column of dimensions $1.1 \mathrm{~cm} \times 70 \mathrm{~cm}$. Blue dextran (Sigma) was used to check the column packing as well as to determine the void volume. The column was calibrated using proteins like melitin (monomeric), cytochrome $c$ from horse heart and ovalbumin. The sample volume loaded varied between 150 and $300 \mu 1$. In the case where ${ }^{1} \mathrm{H} \mathrm{NMR}$ spectra of column fractions are reported, the appropriate fractions were pooled, lyophilized and redissolved in $\mathrm{D}_{2} \mathrm{O}$.

${ }^{1} \mathrm{H}$ NMR spectra were recorded on a Bruker WH-270 FT NMR spectrometer at the Sophisticated Instruments Facility, Indian Institute of Science, Bangalore. No external standard was added to the sample, the $4.76 \mathrm{ppm}$ resonance of $\mathrm{H}_{2} \mathrm{O}$ (in $\mathrm{D}_{2} \mathrm{O}$ ) was taken as an internal réference. All experiments were done at $293 \mathrm{~K}$. Difference nuclear Overhauser effect (N.OE) spectra were obtained by sequential recording of perturbed and normal spectra $(8 \mathrm{~K}$ memory each) using low power on-resonance shifting of the.irradiation frequency, respectively. A delay time of $3.0 \mathrm{sec}$ was used between transients. The difference free induction decay was multiplied by a decaying exponential, prior to Fourier transformation.

\section{Results}

The linear structure of bilirubin IX $\alpha$, the physiologically important bilirubin isomer, is shown in figure 1. Also shown in figure 1 is the structure of cholate, the 


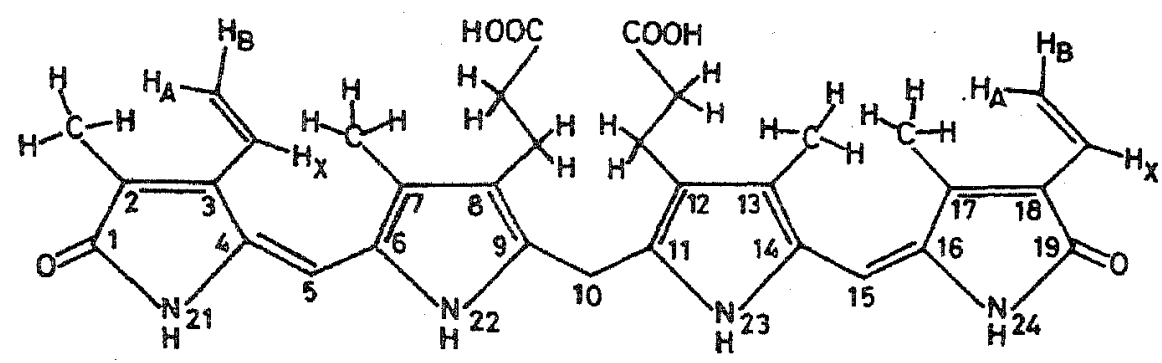

a

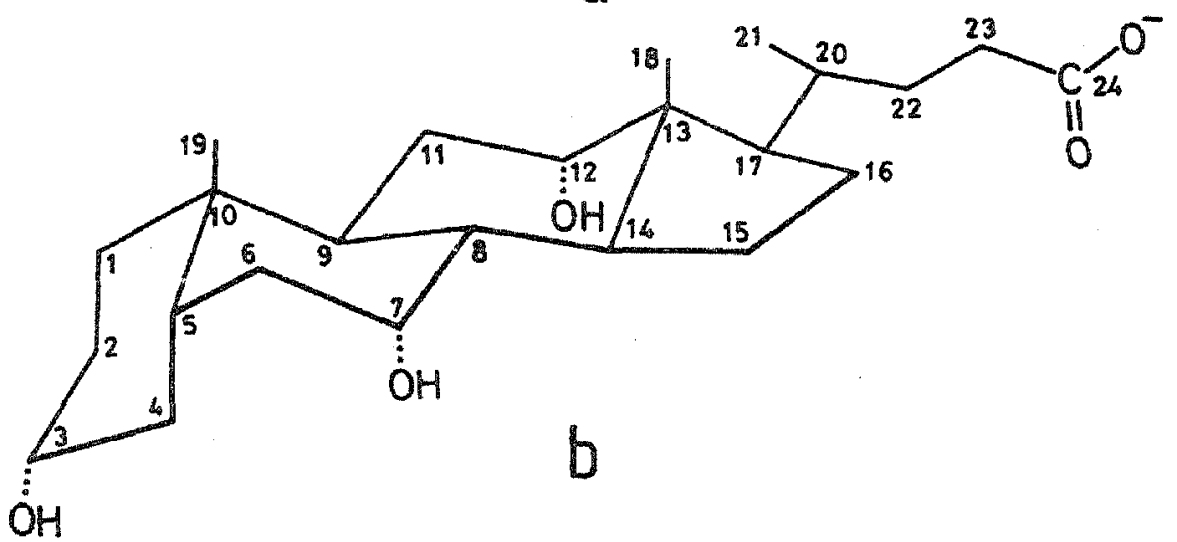

Figure 1. (a) Structure of bilinubin IX $\alpha(42,15 Z$ configuration) with numbering scheme. (b) Structure of cholate with numbering scheme.

bile salt which is the subject of most of the studies described in this report. The other bile salts studied are deoxycholate which lacks a hydroxyl group at position 7 and dehydrocholate, where all the three hydroxyl groups are replaced by keto groups.

\subsection{Ftuorescence}

Figure 2 shows the enhancement of bilirubin fluorescencein the presence of sodium cholate. Bilirubin is practically non-fluorescent in solution at room temperature, the quantum yield being less than $10^{-4}$ (Matheson et al 1975). Binding to serum albumin results in fluorescence enhancement. This increase has been attributed to translational and vibrational immobilization of bilirubin in its bound form (Beaven et al 1973). Bilirubin has also been shown to exhibit enhanced fluorescence when it binds to gramicidin $S$ (Marr-Leisy et al 1985) and symmetrical alkyl diamines (Lahiri and Balaram 1987). Increase of bilirubin fluorescence in the presence of other macromolecules can thus be considered as indicating interaction leading to binding. It is interesting to note in figure 3 that the enhancement of bilirubin fluorescence in the presence of varying concentrations of cholate exhibits a sharp discontinuity , around $13 \mathrm{mM}$, fallowed by a further rise. The critical micelle concentration (CMC) of cholate is known to be between 11 and $13 \mathrm{mM}$ (Roda et al 1983), depending on the presence of salts like sodium chloride. It thus appears that bilirubin binds preferentially to micelles of cholate, There is no observed increase in the fluorescence of bilirubin in the presence of the other bile salts, deoxycholate and dehydrocholate. While the CMC of deoxycholate is $\sim 10 \mathrm{mM}$, that of dehydrocholate is $>250 \mathrm{mM}$ (Roda et al 1983). 


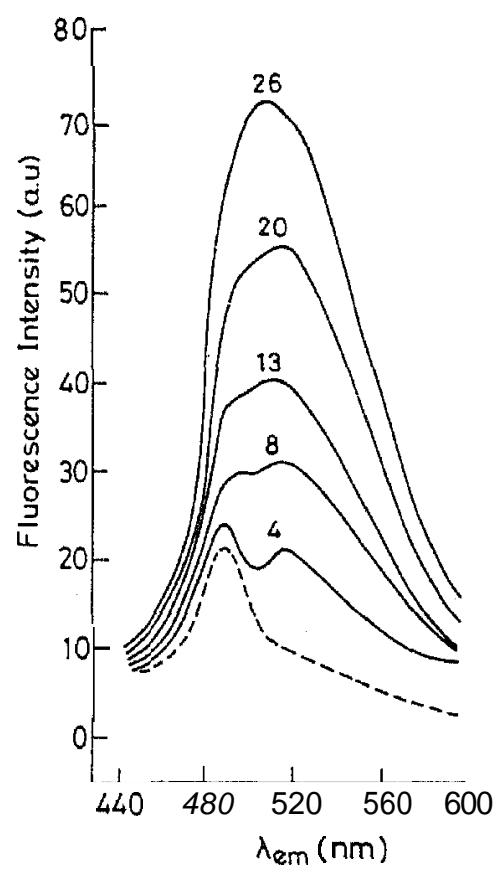

Figure 2. Enhancement of bilirubin $\left(4.8 \times 10^{-6} \mathrm{M}\right)$ fluorescence (arbitrary units) in the presence of cholate in $\mathrm{H}_{2} \mathrm{O}$ at $\mathrm{pH} 10.9,150 \mathrm{mM} \mathrm{NaCl}$. Number over each trace indicates the cholate concentration in $\mathrm{mM} \lambda_{\mathrm{ex}}=420 \mathrm{nrn}$.

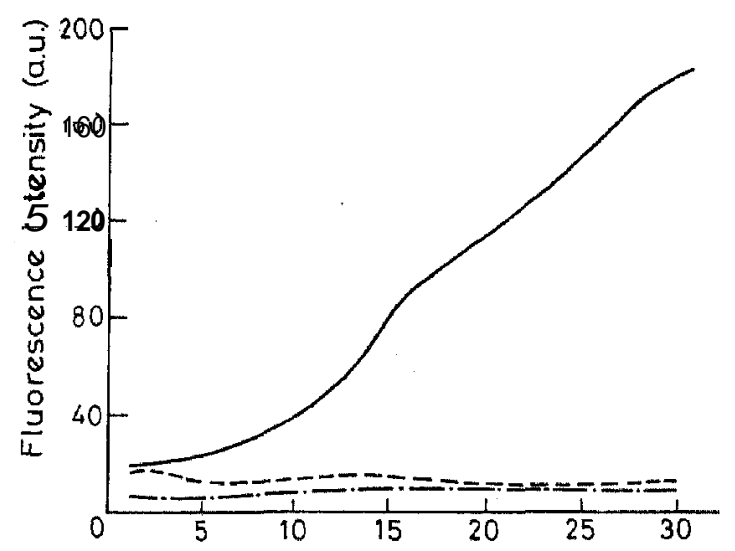

[Bile salt] (mM)

Figure 3. Dependence of bilirubin fluorescence on the concentration of bile salts in $\mathrm{H}_{2} \mathrm{O}, \mathrm{pH} 10.8,150 \mathrm{mM} \mathrm{NaCl} . \mathrm{A}_{n}=420 \mathrm{~nm}, \mathrm{~A}_{\mathrm{m},}=520 \mathrm{~nm} .\left(-4.6 \times 10^{-6} \mathrm{M}\right.$ bilirubin in cholate; $---7.3 \times 10^{-6} \mathrm{M}$ bilirubin in deoxycholate; -. $-7.3 \times 10^{-6} \mathrm{M}$ bilirubin in dehydrocholate.)

\subsection{Circular dichroism}

$\mathrm{CD}$ is a useful technique to monitor bilirubin binding to other molecules since the observation of induced optical activity in the otherwise optically inactive bilirubin is a positive indication of the occurrence of such interactions (Blauer 1983). Such induced optical activity is observed when bilirubin binds to proteins like serum albumins (Brodersen 1982), ligandin (Bhargava et al 1980), arninoazodye-binding protein A (Tipping et al 1976) and chymotrypsin and lysozyme (Blauer 1986). Bilirubin also exhibits induced CD when bound to chiral amines and basic 
polypeptides like poly-L-lysine, melittin and gramicidin $\mathbf{S}$ (Marr-Leisy et al 1985). Induced optical activity has been observed for bilirubin in the presence of sodium deoxycholate (Perrin and Wiisey 1971). Figure 4 shows the induced CD in $7.6 \times 10^{-6} \mathrm{M}$ bilirubin in the presence of $2 \times 10^{-2} \mathrm{M}$ cholate, deoxycholate and dehydrocholate at $\mathrm{pH} 10.5$. The characteristic bisignate $\mathrm{CD}$ pattern is observed with long wavelength positive and short wavelength negative bands, reminiscent of the bilirubin-human serum albumin 1:1 spectrum at $\sim \mathrm{pH} 7$ (Blauer and Harmatz 1972). In the case of bile salts, the long wavelength bands lie between 450 and $470 \mathrm{~nm}$ and the short wavelength band between 375 and $400 \mathrm{nrn}$. The CD parameters for bilirubin in the presence of various bile salts are summarized in table 1. The parameters for bilirubin-human serum albumin are also given for comparison. Figure 5 shows the induced CD spectra for bilirubin in presence of increasing concentrations of cholate. The cholate concentrations studied range from 1 to $20 \mathrm{mM}$. Figure 6 shows a plot of the CD band intensities at 400 and $455 \mathrm{~nm}$ as a function of cholate concentration. The results suggest that induced optical activity is detectable even at premicellar cholate concentrations.

\subsection{Gel permeation chromatography}

To characterize the size of the complex formed by bilirubin and cholate, gel permeation Chromatography was performed on a Sephadex $G-50$ column. A 4:1 ,chelate-bilirubin mixture in water at $\mathrm{pH} 10.5$ was loaded on the column, the eluant

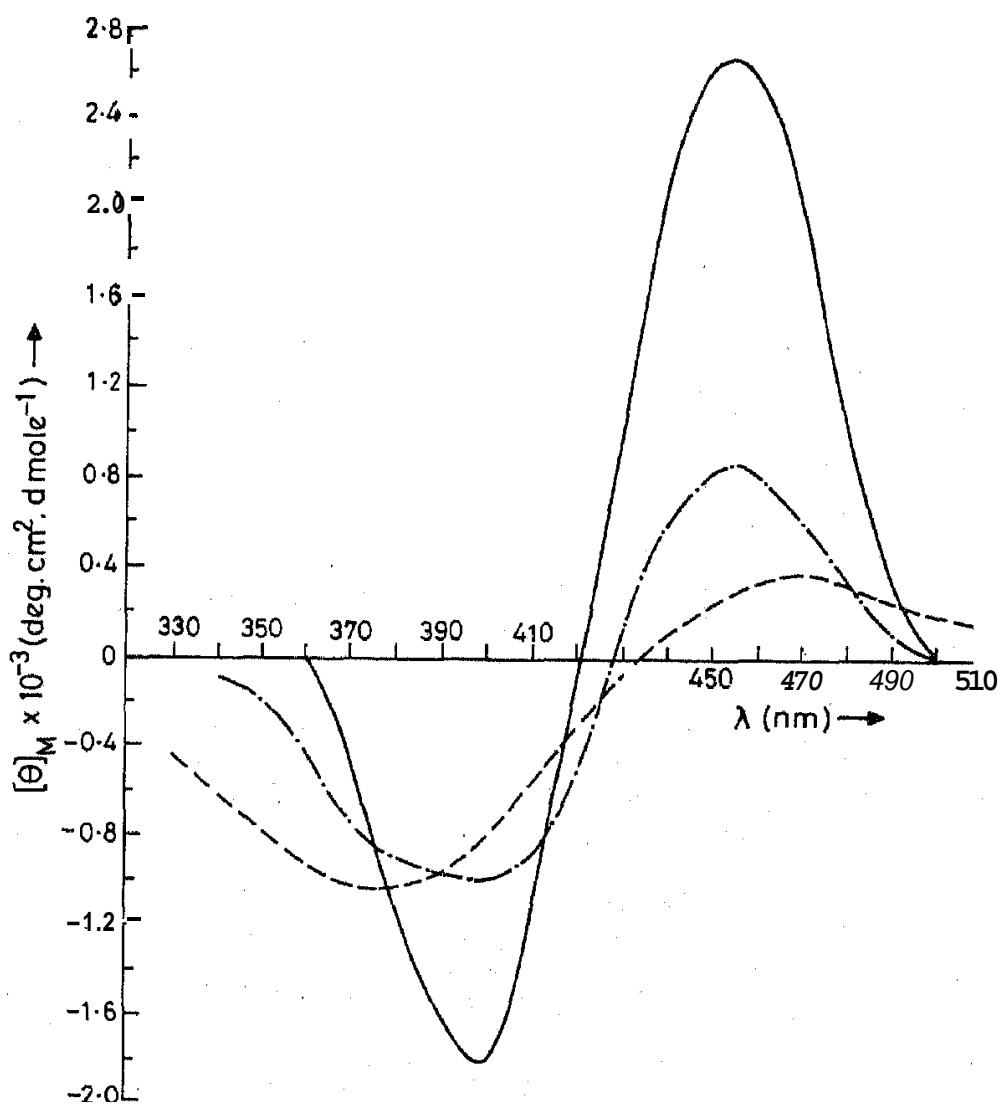

Figure 4. Induced CD spectra of bilirubin $\left(7.6 \times 10^{-6} \mathrm{M}\right)$ in the presence of $20 \mathrm{mM}$ bile salts in $\mathrm{H}_{2} \mathrm{O}, \mathrm{pH} \sim 10.5,150 \mathrm{mM} \mathrm{NaCl}$. Cholate (- - ), deoxycholate $(---)$, dehydrocholate $(\multimap$ ). 
Table 1. CD spectral parameters of bilirubin in presence of bile salts.

Bile salt

Bile salt (HSA)

Bilirubin

(serum albumin)" Solvent concentration (M) concentration (M)

$\lambda_{\mathrm{nm}}\left([\theta]_{\mathrm{M}}\right)^{\mathrm{b}}$

\begin{tabular}{llccc}
\hline Cholate & $\mathrm{H}_{2} \mathrm{O}$, & $2 \times 10^{-2}$ & $7.63 \times 10^{-6}$ & $400\left(-1.0 \times 10^{3}\right) ; 455\left(0.86 \times 10^{3}\right)$ \\
& $\mathrm{pH} 10.6$ & & & \\
Deoxycholate & $\mathrm{H}_{2} \mathrm{O}$, & $2 \times 10^{-2}$ & $7.68 \times 10^{-6}$ & $375\left(-1.04 \times 10^{3}\right) ; 472\left(0.38 \times 10^{3}\right)$ \\
& $\mathrm{pH} 10.5$ & & & \\
Dehydrocholate & $\mathrm{H}_{2} \mathrm{O}$, & $2 \times 10^{-2}$ & $7.68 \times 10^{-6}$ & $398\left(-1.82 \times 10^{3}\right) ; 453\left(2.66 \times 10^{3}\right)$ \\
& $\mathrm{pH} \mathrm{10.5}$ & & & \\
WSA & $\mathrm{H}_{2} \mathrm{O}$, & $3.46 \times 10^{-5}$ & $3.46 \times 10^{-5}$ & $397\left(-1.45 \times 10^{5}\right) ; 448\left(1.97 \times 10^{5}\right)$ \\
& $\mathrm{pH} 8.7$ & & &
\end{tabular}

${ }^{\mathrm{a}}$ Data taken from Marr-Leisy et al $1985 ;{ }^{\mathrm{b}}[\theta]_{\mathrm{M}}$ values as deg. $\mathrm{cm}^{2}$. $\mathrm{d} \mathrm{mole}^{-1}$.

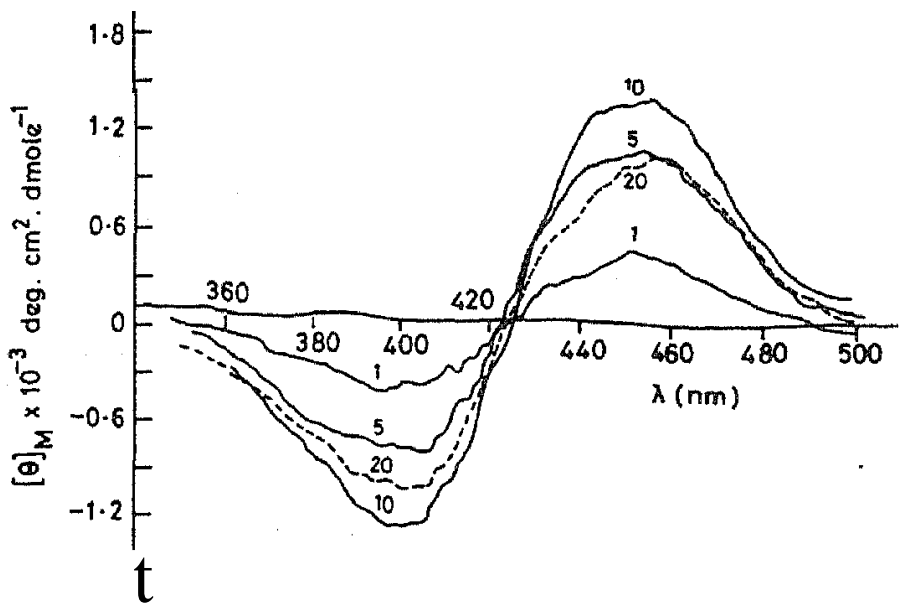

Figure 5. Induced $\mathrm{CD}$ spectrum of $6.9 \times 10^{-6} \mathrm{M}$ bilirubin with increasing cholate concentrations in $\mathrm{H}_{2} \mathrm{O}$ at $\mathrm{pH} 9.2150 \mathrm{mM} \mathrm{NaCl}$. Number over each trace is the concentration of cholate in $\mathrm{mM}$.

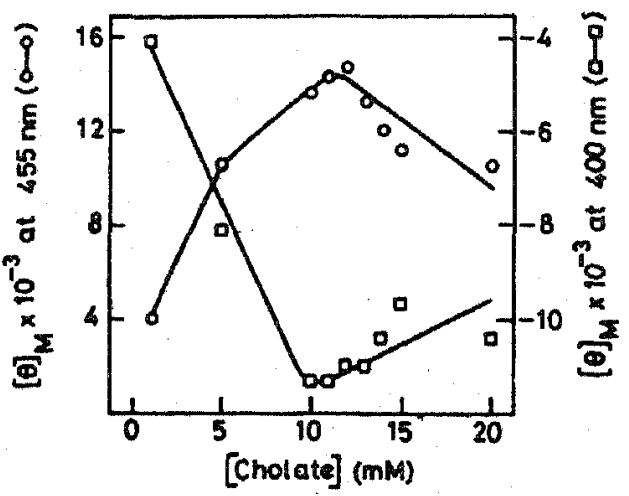

Figure 6. Change in molar ellipticity $\left([\theta]_{M}\right)$ of the bilirubin CD bands at 400 and $455 \mathrm{~nm}$ as a function of cholate concentration. $\left([\theta]_{M}\right.$ values as deg. $\mathrm{cm}^{2}$. dmole $\left.{ }^{-1 /}\right)$. 


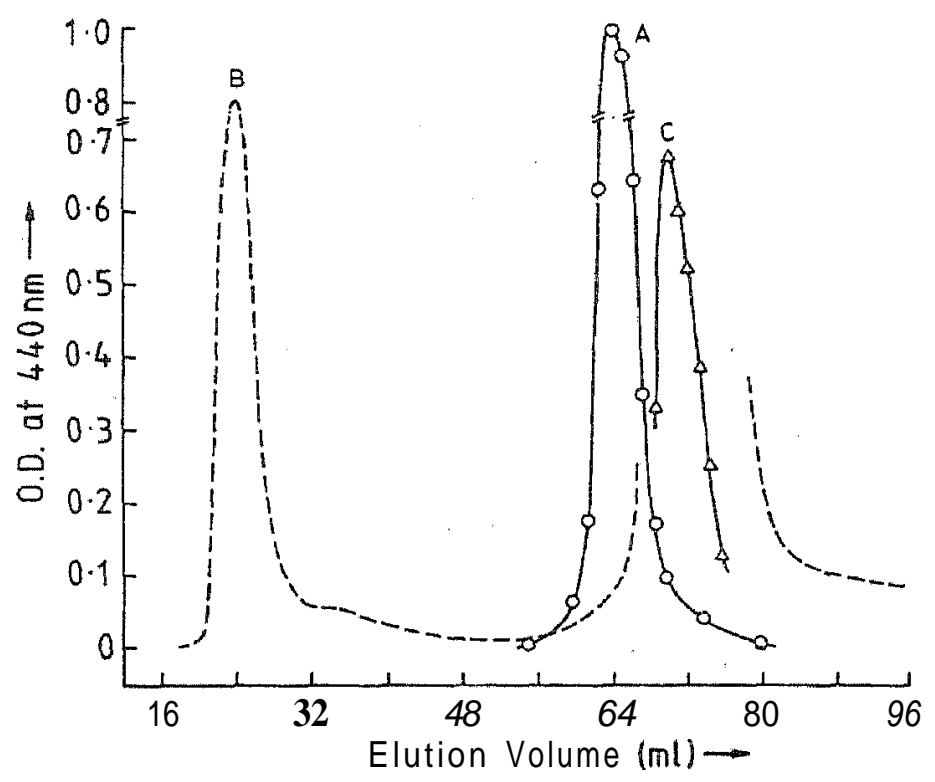

Figure 7. Elution profiles of $15 \mathrm{mM}$ biliu ubin in $60 \mathrm{mM}$ cholate, $\mathrm{pH} 10.5$ through a Sephadex G-50 column. Peak A is obtained when the eluant is $\mathrm{H}_{2} \mathrm{O}$ at $\mathrm{pH} 10 \cdot 8$. Peaks B and $\mathrm{C}$ constitute the two fractions when eluant is at $\mathrm{pH} 6 \cdot 6$. (Absorbanccs of peaks $\mathbf{A}$ and $C^{\prime}$ are of diluted samples.)

being water at $\mathrm{pH} 10 \cdot 8$ or at $\mathrm{pH} 6 \cdot 6$. The elution profile was found to depend on the the same $\mathrm{pH}$, i.e. alkaline, the elution profile, which is obtained by measuring the absorbance of each fraction at $440 \mathrm{~nm}$, shows a single peak (peak A). On the other hand, when the eluant is at a $\mathrm{pH}$ lower than that of the sample loaded, two well-separated peaks (designated as peaks $B$ and $C$ in figure 7 ) are observed. Peak $B$ which is almost at the void volume of the column must be a relatively high molecular weight fraction (Sephadex G-50 has an exclusion molecular weight of $\sim 30,000)$. A cholate solution of similar concentration $(60 \mathrm{mM})$ was also run on the same column under identical conditions. The elution profile of cholate, shown in figure 8, does not depend on the $\mathrm{pH}$ of the eluant and coincides with the position of peak $\mathbf{A}$. To estimate the molecular weights of the column fractions, the column was calibrated using standard proteins and a calibration curve obtained (figure 8 inset). From this curve, the molecular weights of the peaks $\mathbf{A}$ and $\mathrm{C}$ work out to be $\sim 1780$ and $\sim 1120$, respectively.

These column fractions were subjected to $C D$ studies and analysed for their composition using ${ }^{1} \mathrm{H}$ NMR. For the CD spectra, small aliquots were taken from the desired fraction, diluted in water and its $\mathrm{pH}$ adjusted before recording the spectrum. The CD data are summarized in figure 9. It is observed that for peak $\mathbf{A}$, there is no optical activity at a $\mathrm{pH}$ of 11.4 . At $\mathrm{pH} 6 \cdot 7$, weak bands appear, which are stronger at $\mathrm{pH} 2.7$. On the other hand, for peak B, CD spectra are observed at both neutral, as well as alkaline $\mathrm{pH}$. Peak $\mathrm{C}$ exhibits a $\mathrm{CD}$ spectrum at neutral $\mathrm{pH}$ but not at alkaline $\mathrm{pH}$. As compared to the $\mathrm{CD}$ spectrum of peak $\mathrm{B}$, that of peak $\mathrm{C}$ is less intense and has its long wavelength band red-shifted, while its short wavelength band is blue-shifted.

The ${ }^{1} \mathrm{H}$ NMR spectrum of peak $\mathbf{A}$ was found to be identical to that of the bilirubin:cholate 1:4 sample, i.e., the sample which is loaded on the column. 


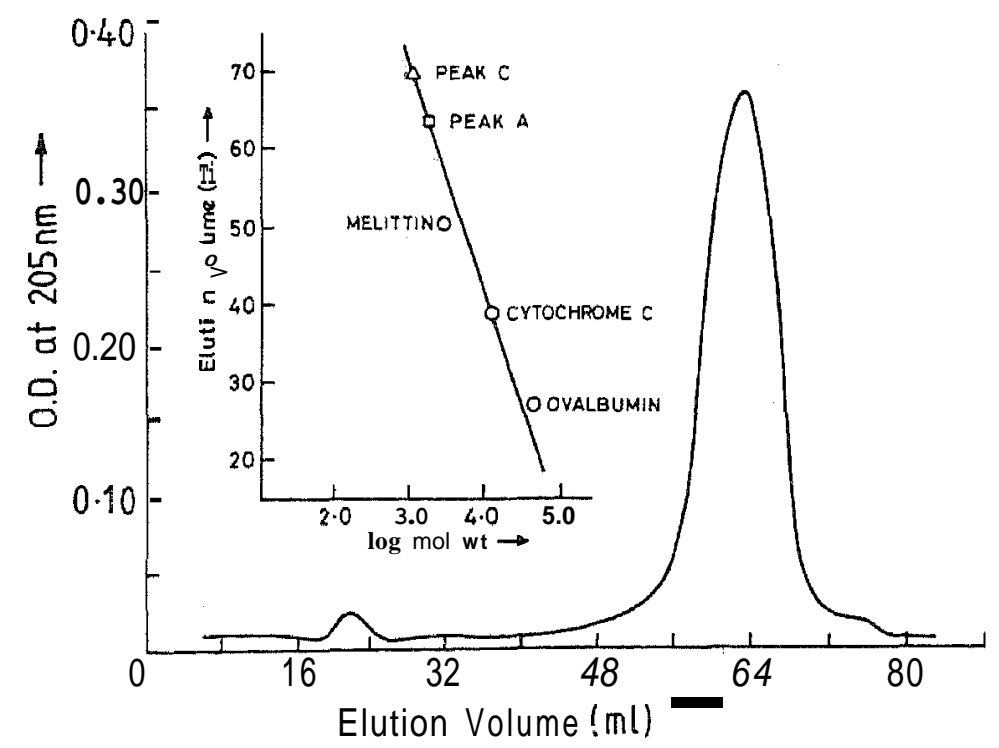

Figure 8. Elution profile of $60 \mathrm{mM}$ cholate through the' Sephadex G-50 column. Inset shows the calibration curve, for estimation of molecular weights, of the column using standard proteins. Marked on this are the peak positions of peaks $\mathbf{A}$ and $\mathbf{C}$.

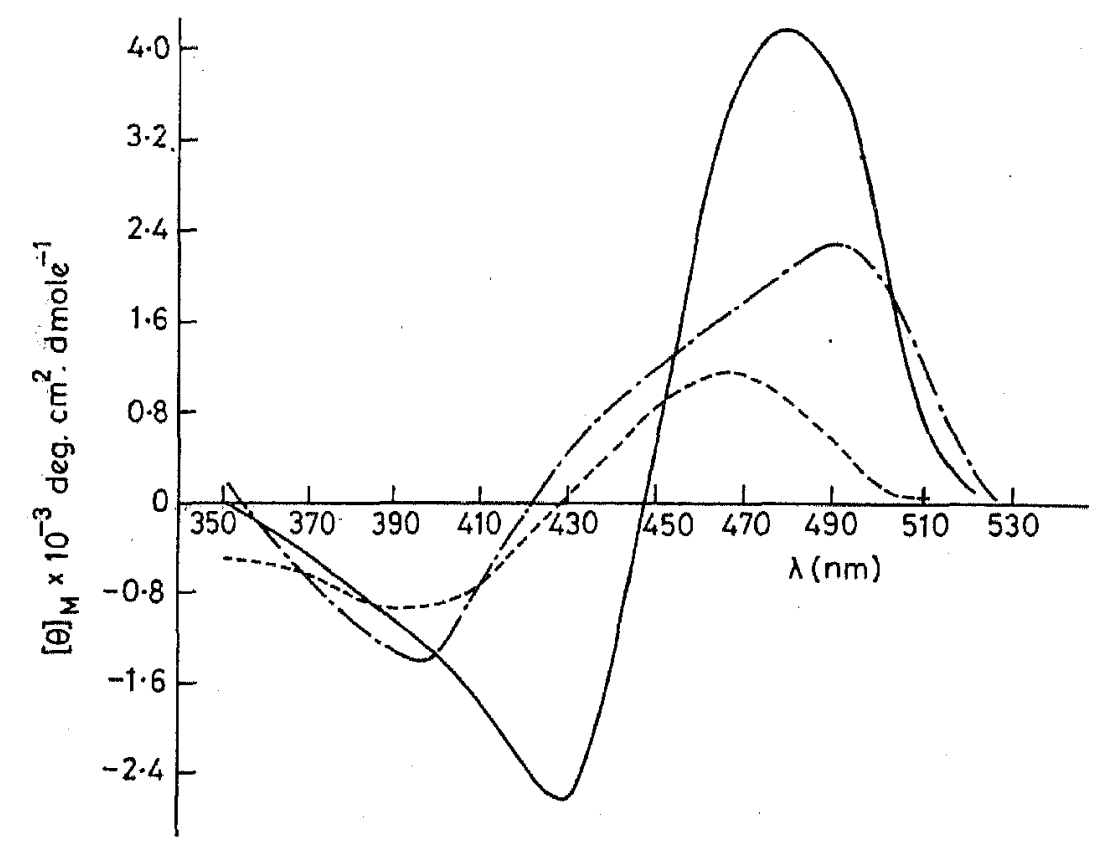

Figure 9. $\mathrm{CD}$ spectra of the column fractions. (-- - ) peak $\mathbf{A}, \mathrm{pH} 2.7$; $7.45 \times 10^{-6} \mathrm{M}$ bilirubin; ( $\longleftarrow$ peak $\mathrm{B}, \mathrm{pH} 6.7,5.76 \times 10^{-6} \mathrm{M}$ bilirubin; (----) peak $\mathrm{C}, \mathrm{pH} 6.7,4.4 \times 10^{-6} \mathrm{M}$ bilirubin.

Figure 10 shows this spectrum along with some of the main assignments. The assignment of the cholate peaks between 0.7 and $4.0 \mathrm{ppm}$ is taken from Waterhous et al (1985), while that of bilirubin in the region 5 and $7 \mathrm{ppm}$ was obtained from decoupling experiments. Integration of the bilirubin and cholate resonances permits an estimate of the stoichiometry of the bilirubin-cholate complex.

Figure 11 shows the ${ }^{1} \mathrm{H}$ NMR spectrum of peak $\mathrm{C}$. Integration of the bilirubin and cholate resonances establishes that the ratio of bilirubin to cholate is $2: 1$, which 


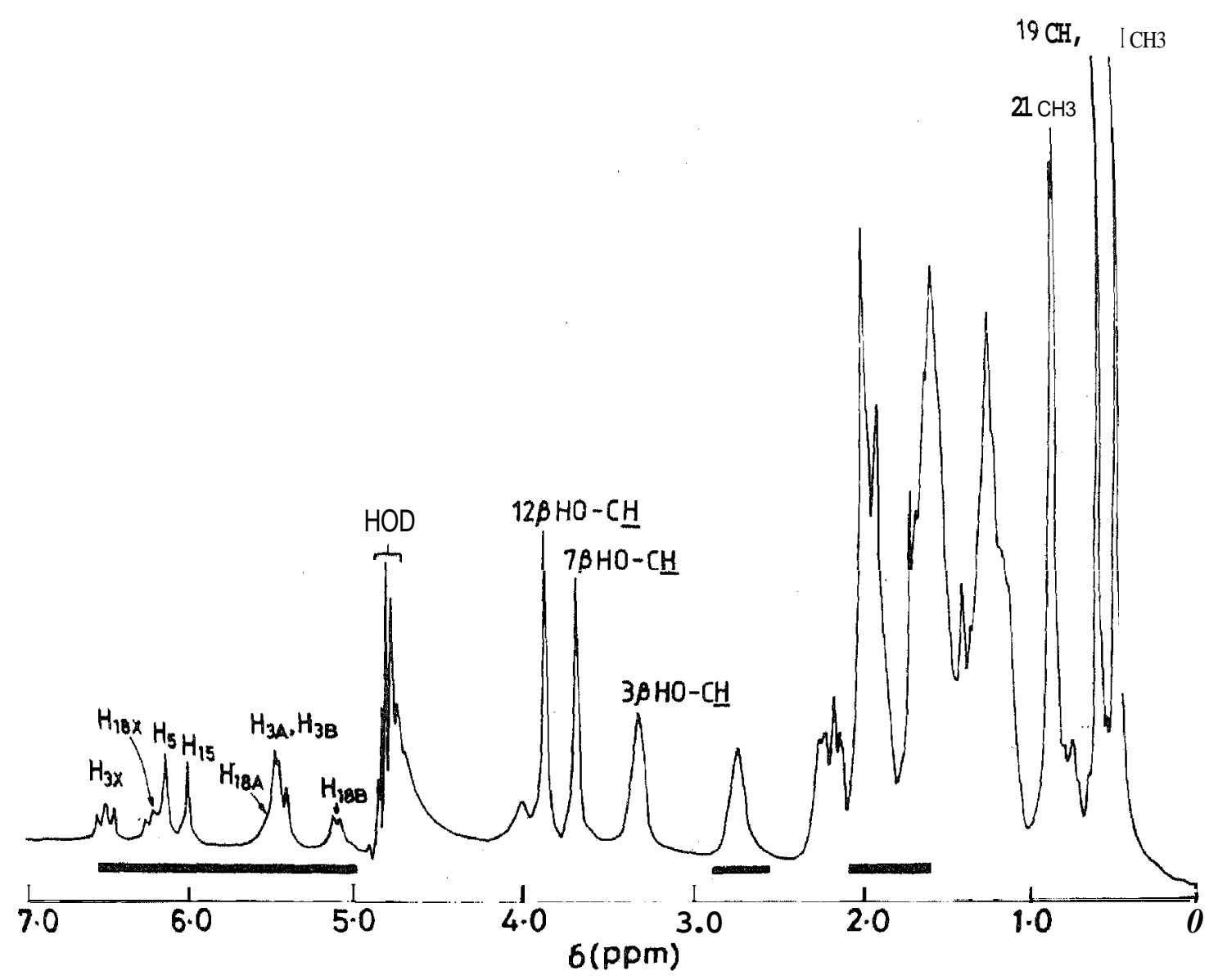

Figure 10. $270 \mathrm{MHz}{ }^{1} \mathrm{H}$ NMR spectrum of $4: 1$ rholate-bilirubin (120 mM cholate, $30 \mathrm{mM}$ bilirubin) in $\mathrm{D}_{2} \mathrm{O}$ at $\mathrm{pH}$ 10.5. Major assignments are shown; the shaded zone indicates the region of bilirubin chemical shifts.

is distinctly different from the composition of the mixture loaded on the column, viz., 1:4 bilirubin:cholate. This is not surprising in itse'-since peak $\mathbf{B}$ obviously corresponds to a large complex with a high cholate to bilirubin ratio, suggesting disproportionation of the original 1:4 bilirubin :cholate mixture.

\subsection{Nuclear Overhauser effects}

The precise nature of intermolecular interactions can, in principle, be probed by the use of nuclear Overhauser effects (Bothner-By 1979). Spatial proximity of protons (hydrogen atoms) can generally be established for interproton distances of $<3 \AA$. In the case of macromolecular and micellar systems the sign of the observed NOE are dependent on the product of the Larmor precession frequency $(w)$ and rotational correlation time $\left(\tau_{c}\right)$, with positive NOE observed for $\omega \tau_{c}<1$, while negative NOE are observed for $\omega \tau_{c}>1$ (Bothner-By 1979). Thus, NOE also provide a means of estimating $\tau_{c}$ values which to turn can be related to the molecular size.

One-dimensional NOE measurements were performed on the 1:4 bilirubin:cholate system. Figure 10 shows the $270 \mathrm{MHz}{ }^{1} \mathrm{H}$ NMR spectrum of a 1:4 mixture of bilirubin and cholate. The olefinic proton resonances of bilirubin are confined to 


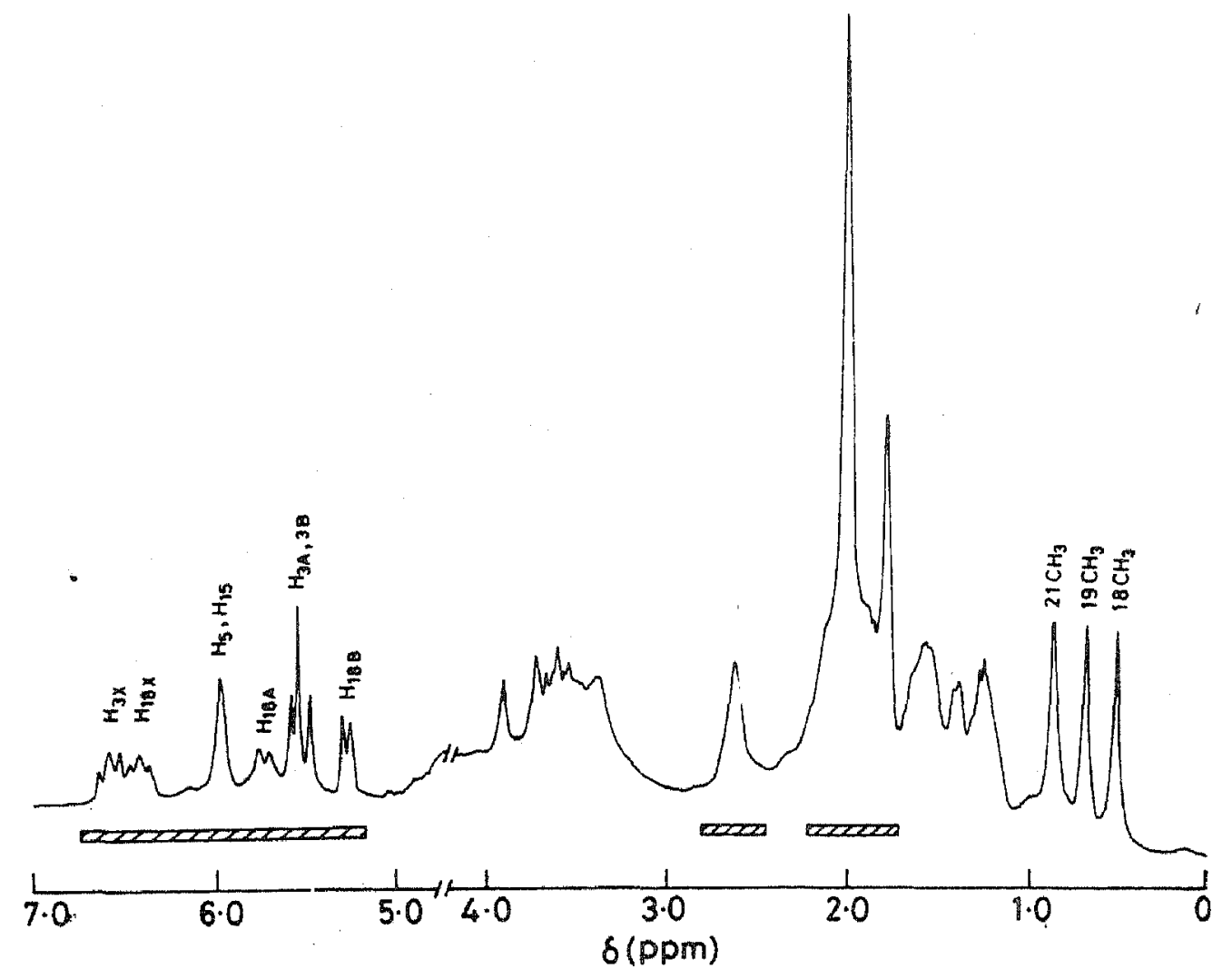

Figure 11. $270 \mathrm{MHz}{ }^{1} \mathrm{H}$ NMR spectrum of peak $\mathrm{C}$ in $\mathrm{D}_{2} \mathrm{O}, \mathrm{pH} 11 \cdot 5$. Specific assignments are indicated. The hatched region corresponds to bilirubin resonances.

the low field region between 5 and $6.7 \mathrm{ppm}$. The methyl resonance corresponding to the $-\mathrm{CH}_{3}$ groups at positions $2,7,13$ and 17 lie between 1.7 and $2.1 \mathrm{ppm}$. The propionate $-\mathrm{CH}_{2}$ protons appear at $2.74 \mathrm{ppm}$. These resonances are marked by a hatched line in figure 10 . All the steroid proton resonances of cholate are limited to the spectral region between 0.5 and $4 \mathbf{p p m}$.

Figure 12 shows the results of representative NOE experiments on the 1:4 bilirubin-cholate mixture. Besides the expected intramolecular NOE, some intermolecular, bilirubin to cholate, NOE are also observed. For example, in figure $12 \mathrm{~b}$ irradration of the bilirubin olefinic methyl resonances clearly shows the expected intramolecular NOE on the $\mathrm{H}_{5}$ and $\mathrm{H}_{15}$ methine protons. The proximity of these protons is not clearly evident from the linear structure shown in figure la. However, it should be noted that rotation about the $C_{5}-C_{6}$ and $C_{14}-C_{15}$ single bonds brings these atoms into close proximity. $\mathrm{NOE}$ are also observed on the $\mathrm{H}_{12}$, $\mathrm{H}_{7}$ and $\mathrm{H}_{3}$ protons of the steroid. These $N \mathrm{NO}^{\circ} \mathrm{E}$ can be rationalized as intramolecular cholate NOE, since the $\mathrm{H}_{2 \beta}, \mathrm{H}_{11 \alpha}, \mathrm{H}_{11 \beta}$ and $\mathrm{H}_{6 \beta}$ protons have been assigned to resonances in this region (Waterhous et al 1985). The spectrum in figure $12 \mathrm{c}$ illustrates the effect of irradiating the $C_{19}$ methyl group of,cholate. Two strong NOE are observed on the cholate protons $\mathrm{H}_{12 \beta}$ and $\mathrm{H}_{7 \beta}$. While the NOE on $\mathrm{H}_{12 \beta}$ can be rationalized as an intramolecular effect due to partial saturation of the proximate $\mathrm{C}_{18}$ methyl group, the observed $\mathrm{NQE}$ on $\mathrm{H}_{7 \beta}$ can only be interpreted in terms of an intermolecular cholate-cholate NOE arising from an aggregated species. An examination of the perspective diagram of cholate in figure $1 \mathrm{~b}$ 


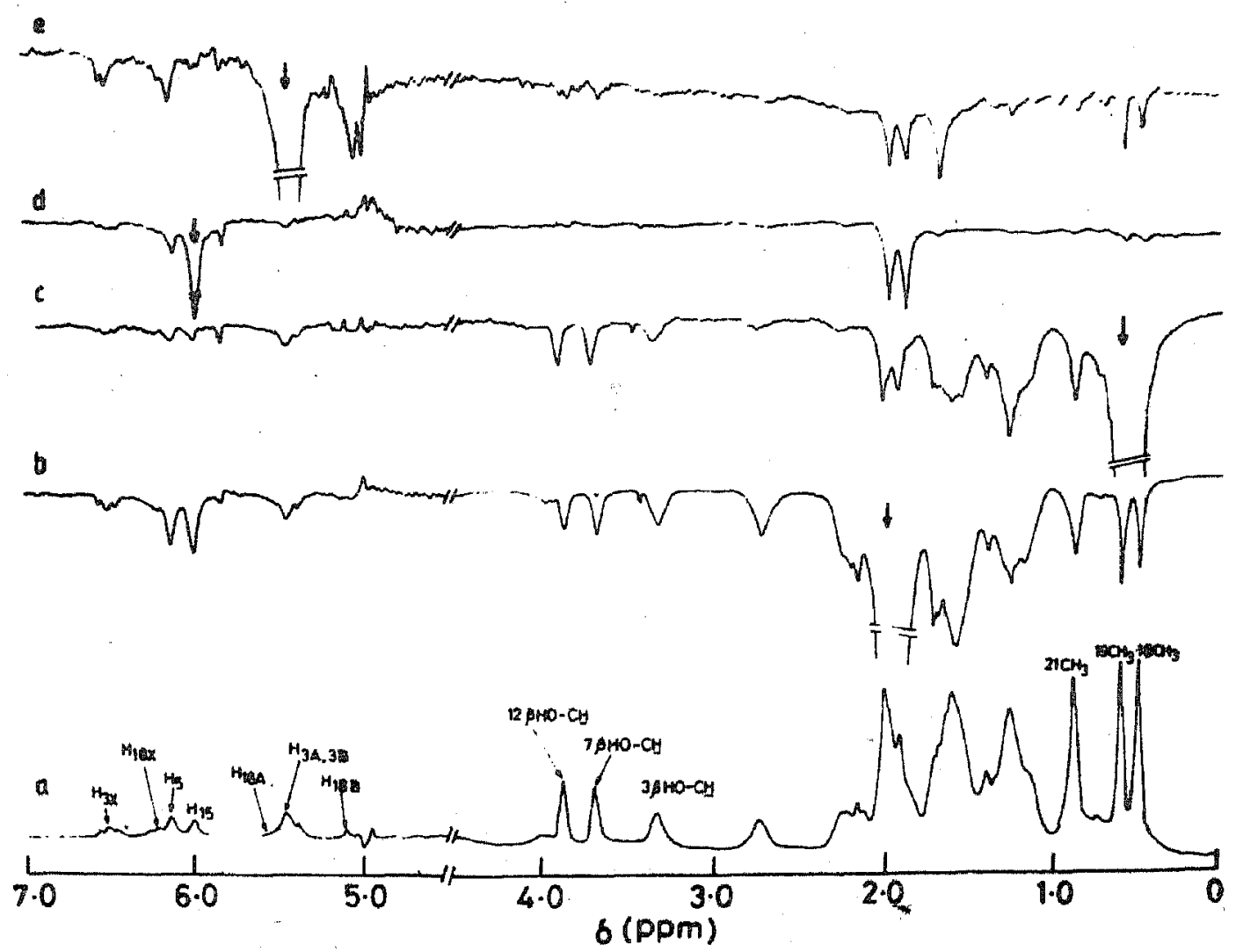

Figure 12. (a) $270 \mathrm{MHz}{ }^{1} \mathrm{H}$ NMR spectrum of $4: 1$ cholate-bilirubin. (b-e) Difference NOE spectra obtained upon irradiation of the resonances indicated by an arrow. The difference NOE spectra were obtained as mentioned in the text and are magnified by a factor of 8. (Bilirubin concentration, $30 \mathrm{mM}$; cholate, $120 \mathrm{mM}$.)

establishes, that the $H_{7 \beta}$ cannot be spatially proximate to either the $C_{18}$ or $C_{19}$ methyl groups. Irradiation of the $\mathrm{H}_{15}$ resonance of bilirubin (figure $12 \mathrm{~d}$ ) results in two clear NOE at 1.91 and $2.01 \mathrm{ppm}$ These correspond to the methyl groups at $\mathrm{C}_{13}$ and $\mathrm{C}_{7}$ of bilirubin. Figure 12e shows the result of an experiment when the olefinic protons on bilirubin, $\mathrm{H}_{18 \mathrm{~A}}$ and $\mathrm{H}_{3 \mathrm{~A}}$, were irradiated. Irradiation of these resonances is expected to lead to NOE on the methyl groups at $C_{2}$ and $C_{17}$ of bilirubin. In addition rotation of the vinyl group at position 3 can result in an NOE to the $\mathrm{C}_{7}$ methyl group also. Indeed, NOE to three bilirubin methyl groups are observed at 1.73, 1.91 and 2.01 ppm. A most interesting feature of figure 12e is the observation of $\mathrm{NOE}$ on the $\mathrm{C}_{18}$ and $\mathrm{C}_{19}$ methyl groups of cholate when the $\mathrm{H}_{3 \mathrm{~A}}$ and $\mathrm{H}_{18 \mathrm{~A}}$ protons of bilirubin are irradiated. A comparison of figures $12 \mathrm{~b}$ and $12 \mathrm{e}$ clearly shows that this is a selective $\mathrm{NOE}$, since no such effect is observed when $\mathrm{H}_{15}$ of bilirubin is irradiated. Thus the spectrum in figure 12e provides clear evidence for an intermolecular interaction between bilirubin and cholate, which brings specific, peripheral olefinic protons into close proximity with the projecting methyl groups on the cholate surface.

All the NOE observed in this study are negative. The magnitudes observed fall in the range 5 to $20 \%$. This suggests that the cholate-bilirubin complex lies in the long correlation limit with $\omega \tau_{c}>1$. For molecules of the size of bilirubin or cholate, monomeric species axe expected to yield positive NOE at $270 \mathrm{MHz}$. Indeed 
positive NOE have been observed in earlier NMR studies of pure bilirubin in chloroform (Kaplan and Navon 1981) and pure cholate in water below the CMC (S Raghothama, unpublished results). The observation of negative NQE provides further support for the presence of aggregated species in solution for the 4:1 cholate-bilirubin mixture.

\section{Discussion}

The interaction of bilirubin with bile acids may be monitored by a variety of spectroscopic techniques. As demonstrated in the present study, fluorescence, CD and NMR methods can be useful in probing bilirubin-cholate interactions. While the observation of spectral changes in the presence of bile salts provides support for an intermolecular interaction, the precise nature of the interacting species is less evident. The absence of detectable spectral changes cannot be taken as evidence for the absence of intermolecular interactions.

These features are clearly illustrated by considering the results of the fluorescence and $C D$ studies in conjunction. In the case of cholate a strong enhancement of bilirubin fluorescence is observed at the CMC of cholate (figure 3). The observation of induced CD bands, however, occur at significantly lower cholate concentrations, with appreciable optical activity even at premicellar Concentrations (figure 5). In this case it appears that fluorescence enhancements accompany micellar solubilization of bilirubin, whereas induced optical activity results even in the case of presumably low molecular weight complexes. Induced optical activity is also observed upon addition of steroid derivatives like dehydrocholate, which is known to be incapable of micellar aggregation at the concentrations used in this study (Roda et al 1983). Deoxycholate, which is known to form micelles at concentrations above $10 \mathrm{mM}$, causes induced optical activity of bilirubin but does notyield a fluorescence enhancement. It is likely that the nature of cholate and deoxycholate micelles may be different leading to a greater conformational flexibility of the bilirubin molecule in the case of the latter. This could lead to enhanced vibrational deexcitation in the deoxycholate case, resulting in a quenching of fluorescence (Braslavsky et al 1983).

The gel permeation studies described earlier afford a means of estimating the size of the micellar complexes under observation and also permit evaluation of the effect of $\mathrm{pH}$ on the stability of these cbmplexes. The 1:4 bilirubin-cholate mixture (15 $\mathrm{mM}$ bilirubin, $60 \mathrm{mM}$ cholate) used in the gel permeation studies was prepared at $\mathrm{pH} 10 \cdot 5$, to facilitate dissolution of bilirubin at such high concentrations. 'Under these conditions, optically clear, intensely absorbing solutions were obtained. Elution profiles were obtained on a Sephadex G-50 column under two distinctly different $\mathrm{pH}$ conditions, viz., $\mathrm{pH} 6.6$ and 10.8 . The characteristics of the various bilirubin-cholate fractions are summarized in table 2. While two distinct fractions (pegks $\mathrm{B}$ and $\mathrm{C}$ ) are obtained at neutral $\mathrm{pH}$, only one peak (A) is obtained. when the elution is performed at alkaline conditions.

Peak A corresponds to a molecular weight of $\sim 1780$ and from an integration of the ${ }^{1} \mathrm{H}$ NMR spectrum a cholate to bilirubin stoichiometry of $4: 1$ is obtained. This species may thus be assigned to a relatively small mixed aggregate composed of approximately 3 to 4 cholate molecules and one bilirubin molecule. Under similar 
Table 2. Characterization of bilirubin-cholate complexes obtained by gel permeation.

\begin{tabular}{|c|c|c|c|c|c|c|c|}
\hline \multirow[b]{2}{*}{$\begin{array}{l}\text { Frac- } \\
\text { tion }\end{array}$} & \multirow[b]{2}{*}{$\begin{array}{c}\text { Stoichiometry } \\
\text { cholate : bilirubin }\end{array}$} & \multirow{2}{*}{$\begin{array}{c}\text { Estimated } \\
\text { molecular } \\
\text { weight }\end{array}$} & \multicolumn{3}{|c|}{$\mathrm{CD}$ parameters at different $\mathrm{pH}$ values } & \multicolumn{2}{|c|}{ NOE } \\
\hline & & & $\begin{array}{c}\text { Acidic } \\
\lambda_{\mathrm{nm}}\left([\theta]_{M}\right)^{a}\end{array}$ & $\begin{array}{c}\text { Neutral } \\
\lambda_{\mathrm{nm}}\left([\theta]_{\mathrm{M}}\right)\end{array}$ & $\begin{array}{l}\text { Alkaline } \\
\lambda_{\mathrm{nm}}\left([\theta]_{\mathrm{M}}\right)\end{array}$ & $\begin{array}{l}\text { Intra- } \\
\text { molecular }\end{array}$ & $\begin{array}{l}\text { Inter- } \\
\text { molecular }\end{array}$ \\
\hline Peak A & $4: 1$ & $\begin{array}{c}\sim 1780 \\
(1805-2212)^{b}\end{array}$ & $\begin{array}{c}395\left(-0.9 \times 10^{7}\right) \\
465\left(1.1 \times 10^{3}\right)\end{array}$ & $\begin{array}{c}397\left(-0.5 \times 10^{3}\right) \\
440\left(0.4 \times 10^{3}\right)\end{array}$ & $\mathrm{C}$ & $\begin{array}{l}\text { Observed } \\
\text { (negative) }\end{array}$ & $\begin{array}{l}\text { Observed } \\
\text { (negative) }\end{array}$ \\
\hline Peak B & Cholate $\mathbf{4}$ bilirubin & $\geqslant 30000$ & d & $\begin{array}{c}430\left(-2.6 \times 10^{3}\right) \\
480\left(4.2 \times 10^{3}\right)\end{array}$ & $\begin{array}{c}435\left(-2.8 \times 10^{3}\right) \\
495\left(2.5 \times 10^{3}\right)\end{array}$ & $\begin{array}{c}\text { Not } \\
\text { determined }\end{array}$ & $\begin{array}{c}\text { Not } \\
\text { determined }\end{array}$ \\
\hline Peak C & $1: 2$ & $\begin{array}{c}\sim 1120 \\
(1575)\end{array}$ & d & $\begin{array}{c}397\left(-1.5 \times 10^{3}\right) \\
490\left(2.3 \times 10^{3}\right)\end{array}$ & $\mathrm{C}$ & $\begin{array}{l}\text { Observed } \\
\text { (Negative) }\end{array}$ & $\begin{array}{c}\text { Not } \\
\text { (observed) }\end{array}$ \\
\hline
\end{tabular}

a $\theta_{1 \text { a }}$ values as deg.cm $\mathrm{cm}^{2} . \mathrm{dmol}^{-1}$;

${ }^{b}$ values in parentheses correspond to molecular weights for the $3: 1$ and $4: 1$ cholate:bilirubin complexes in rhe case of peak A and the $1: 2$ complex for peak $\mathrm{C}$;

c no spectrum observed;

d not determined. 
elution conditions $60 \mathrm{mM}$ cholate eluted at exactly the same position (figure 8). This would correspond to a primary cholate micelle with an aggregation number of approximately 4 to 5 . This is in general agreement with estimates of primary micelle size for bile salts which suggest aggregation numbers between 2 and 10 molecules (Carey and Small 1972). It is likely that the mixed aggregate corresponding to peak A results from incorporation of a single bilirubin molecule into the primary micelle. Under the conditions used in this study, a clear resolution of the differences in aggregate size between the pure primary cholate micelle and mixed micelle cannot be made.

The $\mathrm{CD}$ spectrum of peak $\mathbf{A}$ shows a remarkable sensitivity to the $\mathrm{pH}$ of the medium. While characteristic exciton split bilirubin $\mathrm{CD}$ profiles are observed at $\mathrm{pH}$ 2.4 and 6.7 , no induced $\mathrm{CD}$ spectrum is detected at alkaline $\mathrm{pH}$. It is likely that in the low molecular weight aggregate, bilirubin is relatively more exposed to the solvent environment at $\mathrm{pH} 11.4$. The absence of $\mathrm{CD}$ bands can then be due to conformational flexibility or due to equal populations of both right- and left-handed chiral forms. At lower $\mathrm{pH}$, the structure of the aggregate may be distinctly different with bilirubin now occupying a more sequestered position. Under these conditions, chiral perturbations are more likely to result in an induced $\mathrm{CD}$ spectrum. Exactly similar $\mathrm{CD}$ behaviour was observed for a 4: 1 cholate: bilirubin mixture, which had not been subjected to gel filtration. NOE studies of peak A yielded both intra and intermolecular NOE similar to those described for the 4:1 cholate: bilirubin mixture.

A sudden drop in $\mathrm{pH}$, when the eluant is at $\mathrm{pH} 6 \cdot 7$, results in a fragmentation of the mixed bilirubin-cholate micelles: A marked $\mathrm{pH}$ dependence has also been observed in the bilirubin-human serum albumin case (Brodersen 1982) which has been attributed to the presence of a second type of bilirubin-albumin complex. This complex, which is different from the 1: 1 complex, is a large aggregate of bilirubin acid and albumin in molar proportions of about 300:1. Such aggregates can be dissolved on addition of sodium hydroxide, and they leave a 1:1 complex and an excess of bilirubin dianion in solution.

It seems that a similar process is taking place in the bilirubin-cholate case too, with the formation of a 2:1 complex (bilirubin:cholate), and a large complex, which elutes in the void volume of the column and which has very little bilirubin solubilized in a large micellar cholate aggregate.

The stoichiometry of the complex corresponding to peak $\mathrm{C}$ is unambiguously established by its proton NMR spectrum (1:2 cholate bilirubin). The estimated molecular weight of $\sim 1120$ suggests that this fraction corresponds to a trimeric complex with one cholate and two bilirubin molecules. In this case a characteristic $\mathrm{CD}$ spectrum was observed at neutral $\mathrm{pH}$ but no optical activity could be detected at alkaline $\mathrm{pH}$. Presumably the trimeric complex readily dissociates at high $\mathrm{pH}$ into its individual components. An interesting feature of peak $\mathrm{C}$ is the absence of any intermolecular NOE suggesting that the disposition of cholate and bilirubin molecules is appreciably different from that in peak $\mathrm{A}$.

Peak $B$ is undoubtedly a high molecular weight fraction containing a large excess of cholate and can be best described as a micellized bilirubin fraction. In this case induced $\mathrm{CD}$ spectra "were observed at both neutral and alkaline $\mathrm{pH}$.

In the present study NOE have been used to provide definitive evidence for close intermolecular interactions in the $4: 1$ cholate : bilirubin system. A particular point 
of interest is the observation of relatively large intramolecular NOE for both bilirubin and cholate molecules. Earlier studies of bilirubin in organic solvents like chloroform and dimethyl-sulfoxide (Kaplan and Navon 1981, 1982) have yielded limited $\mathrm{NH} \leftrightarrow \mathrm{NH}$ NOE between pyrrole $\mathrm{NH}$ protons and $\mathrm{NH} \leftrightarrow \mathrm{CH} N \mathrm{NOE}$ between pyrrole $\mathrm{NH}$ and the bridging methylene protons. In the present study, several NOE have been observed between the olefinic protons of the vinyl group and the bridging methine groups and the peripheral methyl groups. Some of these NOE are in fact conformation sensitive NOE, which provide information about the orientations of the pyrrole groups about the $\mathrm{C}_{5}-\mathrm{C}_{6}$ and $\mathrm{C}_{14}-\mathrm{C}_{15}$ single bonds. The observation of these NOE is undoubtedly facilitated by the fact that the complexes have long correlation times, which result in larger magnitudes of the cross relaxation parameters.

A more extensive analysis of the observed NOE together with the $\mathrm{CD}$ results may provide a greater insight into the conformations of bilirubin packaged into cholate aggregates.

\section{Acknowledgement}

We thank S Raghothåma for carefully performing the difference NOE experiments.

\section{References}

Beaven G H, d'Albis A and Gratzer W I3 1973 Eur. J. Biochern. 33500.

Bhargava M M, Ohmi N, Listowsky I and Arias M I 1980 J. Biol. Chem. 255718

Bickel M H and Minder R 1970 Biochem. Pharmacol. 192437

Blauer G 1983 Israel J. Chem. 23201

Blauer G 1986 Biochim. Biophys. Acta 884602.

Blauer $G$ and Harmatz D 1972 Biochim. Biophys. Acta 27889

Bothner-By A A 1979 in Magnetic resonance in biology (ed.) R. G Shulman (New York: Academic Press) p. 177

Braslavsky S E, Holzwarth A R and Schaffner K 1983 Angew. Chem., Int. Ed. Engl. 22656

Brodersen R 1982 in Bilirubin (eds) K P M Heirwegh and S B Brown (Boca Raton, Fl: CRC Fress) vol. 1, p. 75

Brown S B and Troxler R F 1982 in Bilirubin (eds) K P M Heirwegh and S B Brown (Boca Raton, Fl: CRC Press) vol. 2, p.1

Carey MC and Koretsky A 1979 Biochern. J. 179675

Carey M C and Small D M 1972 Arch. Intern. Med. 130506

Goresky C A, Naddad H H, Kluger W S. Nadeau B E and Bach 6 G 1974 Can. J. Physiol. Pharmacol. 52389

Kaplan D and Navon G 1981 J. Chem. Sac. Perkin II 1374

Kaplan D and Navon G 1982 Biochem J. 201605

Lahiri K and Balaram P 1987 J. Biosci. 11485

Marr-Leisy D, Lahiri K and Balaram P 1985 Int. J. Pept. Protein Res. 25290

Matheson I B C, Faini G J and Lee 33975 Photochem. Photobiol. 21135

McDonagh A F and Assisi F 1972 Biochem. J. 129797

Meuwissen-J A T P and Heirwegh K P M 1982in Bilirubin (eds) K P M Heirwegh and S B Brown (Boca Raton, Fl: CRC Press) vol. 2, p. 39

Ostrow J and Celic I 1984 Hepatology 4385 
Perrin J H and Wilsey M 1971 J. Chem. Soc., Chem. Commun.769

Reuben A 1984 Hepatology $4212 S$

Reuben A, Howell K E and Boyer J L 1982 J. Lipid Res. 231039.

Roda A, Hofmann A F and Mysels K J 1983 J. Biol. Chem. 2586362

Scharschmidt B F and Schrnid R 1378 J. Clin. Invest. 621122

Tipping E, Ketterer B, Christodoulides L and Enderby G 1976 Biochem. J. 157211

Waterhous D V, Barnes S and Muccio D D 1985 J. Lipid Res. 261068 